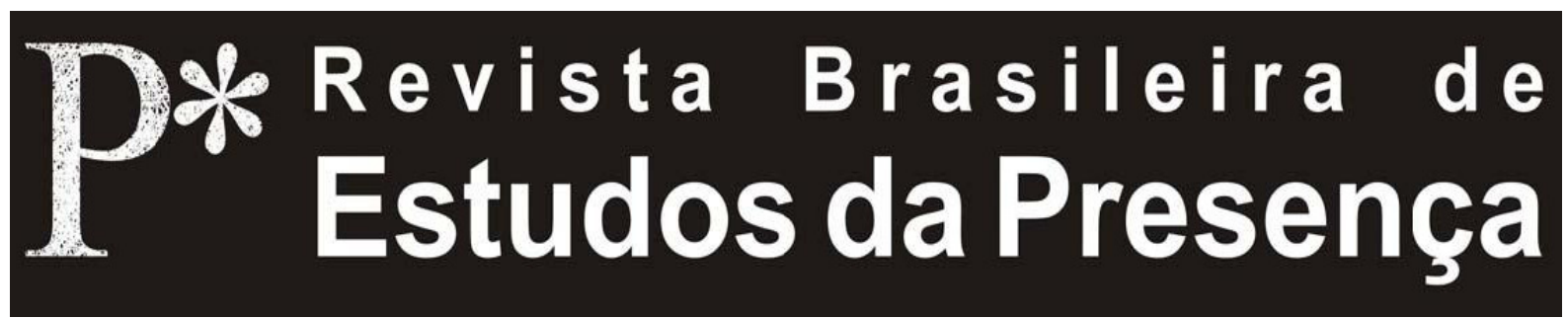

DOI - http://dx.doi.org/10.1590/2237-266038593

ISSN 2237-2660

\title{
"Cantem, pode acontecer alguma coisa": em torno dos cantos e do cantar nas investigações do Workcenter of Jerzy Grotowski and Thomas Richards
}

\begin{abstract}
Tatiana Motta Lima Universidade Federal do Estado do Rio de Janeiro - UNIRIO, Rio de Janeiro, RJ, Brasil
\end{abstract}

RESUMO - "Cantem, pode acontecer alguma coisa": em torno dos cantos e do cantar nas investigaçóes do Workcenter ofJerzy Grotowski and Thomas Richards - Este texto propõe explorar, no trabalho do Workcenter of Jerzy Grotowski and Thomas Richards, as práticas baseadas nos cantos de tradição, a partir de uma relação estreita entre artesanias (modos de fazer) e modos de existência (ou de subjetivação). Problematiza-se ainda a relaçáo entre tradição e investigação. A partir dessas relações, pergunta-se sobre que experiências e que competências - no dizer de Grotowski, Richards e Biagini - estão relacionadas a esses cantos e ao ato de cantá-los. O texto indaga, por fim, sobre a função dos cantos e o lugar do cantante.

Palavras-chave: Grotowski. Workcenter of Jerzy Grotowski and Thomas Richards. Subjetividade. Trabalho sobre Si. Cantos de Tradição.

ABSTRACT - "Sing, something might happen": about the songs and the act of singing in the research of the Workcenter of Jerzy Grotowski and Thomas Richards This text explores, in the work of the Workcenter of Jerzy Grotowski and Thomas Richards, traditional songs-based practices, on he basis ot the powerful relationship between crafts (ways of doing) and modes of existence (or subjectivation). It also discusses the relationship between tradition and research. A question arises from these relationships about what experiences and skills - in the words of Grotowski, Richards and Biagini - are related to these songs and to the act of singing them. Finally, the text discusses the function of the songs and the place of the singer.

Keywords: Grotowski. Workcenter ofJerzy Grotowski and Thomas Richards. Subjectivity. Work on the Self. Traditional Songs.

RÉSUMÉ - “Chantez, il peut se passer quelque chose": autour des chansons et du chant dans les recherches du Workcenter of Jerzy Grotowski and Thomas Richards - Dans ce texte, l'auteur propose d'explorer, dans le travail du Workcenter of Jerzy Grotowski and Thomas Richards, les pratiques fondées sur des chants traditionnels, à partir d'une relation étroite entre l'artisanal (manières de faire) et les modes d'existence (ou de subjectivation). Il problématise aussi la relation entre la tradition et la recherche. À partir de ces relations, il cherche à identifier quelles expériences et quelles compétences - dans le discours de Grotowski, Richards et Biagni - sont liées à ces chants et à l'action de les chanter. Enfin, l'auteur s'interroge sur la fonction des chants et sur la place du chanteur.

Mots-clés: Grotowski. Workcenter of Jerzy Grtowski and Thomas Richards. Subjectivité. Travail sur Soi. Chants Traditionnels. 


\section{Se Deus existe, ele cuida da nossa vida espiritual. E se ele não existe?}

No trabalho de Grotowski fica evidente, principalmente a partir da fase do Teatro das Fontes, a presença de um deslizamento entre os campos da arte e da espiritualidade. Por outro lado, também não é difícil perceber como o artista (e também Richards e Biagini, diretores do Workcenter) evita utilizar o termo espiritualidade para referir-se às suas investigaçóes. Nas suas aulas do Collège de France, Grotowski afirmou que, embora fosse possível dizer que se tratava, no Workcenter, de uma prática espiritual, ele preferia utilizar uma terminologia que não tivesse esse 'lado um pouco fácil e sentimental'. Dizia ainda que a própria noção de espírito havia desaparecido em nossa época: que, para os franceses, era sinônimo de mente e para os americanos estava ligada ao que chamou de sopa new age.

Ainda que possa parecer paradoxal, a questão da espiritualidade foi, para Grotowski, uma questão terrena e corpórea. Era no emaranhado da existência, da nossa intimidade, das relaçóes, que ele via tanto o aprisionamento, a mortificação e a mecanização da vida, quanto a possibilidade de criaçáo e a potência de transformação. Uma pergunta de Grotowski, registrada em filme de 1963 e feita em tom de blague, revela exatamente esse ponto. Após afirmar que o problema principal de seu teatro tinha se tornado a vida interior do homem, ele completava: "Nós colocamos os espectadores diante da seguinte questão: Se Deus existe, então, ele cuida da nossa vida espiritual, mas, e se ele não existe?"' A vida espiritual do homem, sua alma, o conhecimento que pode ter de si mesmo é, para Grotowski, affair do próprio homem.

Tenho experimentado a expressão trabalho sobre si para refletir sobre esse deslizamento entre arte e espiritualidade na obra de Grotowski. A expressão é stanislavskiana, mas está bastante presente no léxico de Grotowski e de seus herdeiros. Porém, se as palavras espiritualidade e/ou sagrado colocavam um determinado tipo de problema - sua vinculação com seitas, religiôes, dogmas e mesmo com a figura de um Deus -, a expressão trabalho sobre si, em nossa época de ênfase no indivíduo, também pode ser enganosa. Precisamos entender de que trabalho e, principalmente, de que si se trata aqui antes de usarmos a expressáo como ferramenta de análise. $\mathrm{Ou}$ podemos, ao contrário, nos debruçar sobre as práticas do Workcenter, para entender a expressão trabalho sobre si como palavra já praticada ${ }^{2}$ 
e não como modelo de ação. Então, vou me aproximar da expressão trabalho sobre si, investigando determinadas noçóes de artesania e de subjetividade ligadas aos cantos e ao ato de cantar nas pesquisas realizadas no Workcenter. Sem dúvida, na investigação do Workcenter, há uma relação estreita entre os modos de fazer, a artesania - o trabalho, e os modos de existência ou de subjetivação - o si. Poderíamos também ampliar o foco e dizer que existe uma relaçáo também estreita (e, talvez, uma determinada reinvenção da relação) entre tradição e investigação.

Grande parte do trabalho do Workcenter se realizou e se realiza em torno de cantos de tradiçáo. Sáo cantos, principalmente, mas não só, de origem afro-caribenha (vindos - também principalmente - do vudu haitiano). Investigarei as experiências que - no dizer de Richards e Biagini - estão relacionadas a esses cantos, ou melhor, ao ato de cantá-los. Perguntarei sobre as noçóes de competência ou técnica implicadas nessa investigação. Comecemos com Biagini:

No Workcenter, a arte é veículo de um trabalho sobre si: o itinerário é aquele de uma possível transformação pessoal. Transformação não no sentido teatral (um ator que transforma seu comportamento cotidiano no comportamento de um personagem); em vez disso, transformação na qualidade de habitar no mundo do ser humano, entre outros seres humanos. Acontece internamente, mas está em relação direta com o que ocorre externamente. $\mathrm{O}$ trabalho sobre os cantos e sobre as Actions criadas com os cantos pode permitir que o atuante encontre o espaço para a transformação de qualidade na própria presença: na percepção do mundo e de si mesmo no mundo. Só se compreendermos que uma técnica não é um simples procedimento mecânico poderemos considerar esse approche (Biagini, 2007a [2003-2006], p. 403-404).

Três coisas vão me interessar nessa citação:

A primeira é a relação entre conhecimento, trabalho sobre si e transformação de si. A segunda diz respeito à questáo da percepção do mundo e de si mesmo no mundo. $\mathrm{Na}$ citação, essa percepção alargada aparece como sinônimo de presença. E a terceira é a noção de técnica que aqui se insinua: uma técnica que náo se confunde com um procedimento mecânico. Obviamente, os três pontos sobre os quais vou refletir estáo relacionados no trabalho do Workcenter. Separo-os apenas para facilitar a análise. 
Foucault afirmava nas suas aulas de 1982, no Collège de Fran$c e$, que, em um determinado momento da nossa civilização, que ele chamou, em tom de pilhéria, de 'momento cartesiano', separou-se o acesso ao conhecimento de uma antes necessária transformação/ assunção/purificação/transfiguração/de si (os nomes eram diferentes para as diferentes escolas greco-romanas). O conhecimento, a verdade, teria passado, então, a ser da ordem do racional e não implicava mais uma transformação - ética/espiritual - do sujeito. Cito: "A história da verdade entrou no seu período moderno no dia em que admitimos que o que dá acesso à verdade, as condiçóes segundo as quais o sujeito pode ter acesso à verdade, é o conhecimento e tão somente o conhecimento" (Foucault, 2010, p. 17-18). E as condiçóes para isso, segundo Foucault, são: as regras formais do método, certas condiçóes extrínsecas (o louco não conhece a verdade), culturais (ter realizado estudos, formação, inscrever-se em algum consenso científico) e morais (esforço, honestidade intelectual, etc.). Foucault, com seu humor peculiar, conclui que, nesse mundo cartesiano [e pós-cartesiano], o sujeito, tal como é - sem precisar se transformar, ou transformar a sua percepção de si -, é capaz de verdade, mas que a verdade, tal como ela é - uma verdade baseada nos pressupostos elencados acima -, não é mais capaz de salvar o sujeito. $\mathrm{O}$ mundo tornou-se objetivo (e objeto), diferente do mundo greco-romano visto como ocasiáo de conhecimento e transformação de si, como lugar de emergência - de aparição ou criação ou rememoração, não importa - de si, de uma subjetividade.

Podemos dizer, para continuarmos com Foucault, que no Workcenter continua a existir uma verdade etopoiética: "[...] uma verdade que pode antes ser lida na trama dos atos realizados e das posturas corporais, do que decifrada no segredo das consciências ou elaborada no gabinete dos filósofos profissionais" (Gros, 2010, p. 478).

Durante toda a Antiguidade Greco-Romana, diz Foucault, o tema da filosofia (como ter acesso à verdade?) e a questão da espiritualidade (quais as transformaçóes no ser mesmo do sujeito para que possa ter acesso à verdade?) jamais estiveram separados. O que Foucault traduziu como cuidado de si ou inquietude de si estava relacionado a "[...] algumas ações [de diferentes escolas na Grécia e na Roma antigas], ações que são exercidas de si para consigo, açóes pelas quais nos assumimos, nos modificamos, nos purificamos, nos

Tatiana Motta Lima - "Cantem, pode acontecer alguma coisa”: em torno dos cantos e do cantar nas investigaçóes do Workcenter of Jerzy Grotowski and Thomas Richards R. bras. est. pres., Porto Alegre, v. 3, n. 1, p. 220-240, jan./abr. 2013.

Disponível em: <http://www.seer.ufrgs.br/presenca> 
transformamos e nos transfiguramos" (Foucault, 2010, p. 12). Era necessário que o sujeito se tornasse outro que não ele mesmo (Foucault, 2010, p. 16) ou, na traduçáo para o espanhol: se convertesse em distinto de si mesmo (Foucault, 2009, p. 33) para ter direito de acesso à verdade $\mathrm{O}$ ato de conhecer - no cuidado de si-, ao mesmo tempo em que transformava o sujeito, só podia ocorrer a partir da transformação do próprio sujeito que conhece. Uma imagem trabalhada por Foucault é aquela do sujeito constituir-se permanentemente como médico e doente de si mesmo (Gros, 2010).

Talvez a partir dessa discussão seja mais fácil entender a ênfase de Grotowski e do Workcenter no fazer. E perceber que não se trata de qualquer fetichização da empiria ou da técnica per si. Poderíamos dizer que náo se trata de um fazer qualquer, mas da realizaçáo de uma ação, de um ato, de um trabalho, no qual conhecer e conhecer-se (como outro de si) estejam imbricados. Vejamos essa citação retirada do texto Le Performer:

O homem de conhecimento dispóe do doing, do fazer e não de ideias ou de teorias. Que faz pelo aprendiz o verdadeiro teacher? Ele diz: faça isso. O aprendiz luta para compreender, para reduzir o desconhecido ao conhecido, para evitar fazer. Pelo fato mesmo de querer compreender, ele resiste. Ele pode compreender, se faz. Ele faz ou não. O conhecimento é um problema de fazer (Grotowski, 1988 $[1987]^{3}$, p. 53).

O que Grotowski valora aqui é um conhecimento que, sendo da ordem de um fazer do sujeito, também produza - ou faça desaparecer - $o$ sujeito; um fazer que, ao mesmo tempo, crie/relembre novos modos de subjetivação. $\mathrm{O}$ sujeito que quer compreender não pode conhecer. Aquele capaz de conhecer é um outro; é aquele que náo mais se esforça por reduzir o desconhecido ao conhecido, que pode produzir conhecimento. Conhecer é - e só ocorre se o homem/ atuante é capaz de - produzir, aceitar, relembrar, alargar a percepção para outros modos de subjetivação, outros modos de existência. Nesse sentido, apenas um outro de si ou um fora de si poderia conhecer ${ }^{4}$.

II

Assim, é sobre outras percepçóes de si e do mundo - estariam separados? - que se trabalha a partir dos cantos e do cantar. Precisa-se ir além daqueles modos de perceber o mundo e/ou de perceber a si mesmo que impedem a experimentação de outros modos de subjeti- 
vação, que prendem/submetem o sujeito a certas formas mecânicas e estereotipadas de agir, sentir e pensar.

Em Grotowski, trata-se de um trabalho sobre o alargamento e não de uma alteração - da percepção, da consciência, como bem salientou Attisani:

[...] a intensidade com que Grotowski acena não é para ser entendida como uma alteração do estado de consciência, mas como um alargamento. [...] o alargamento continua a compreender dentro de si a consciência ordinária e isso faz com que, mesmo que nos dois casos a transformação seja temporária, no segundo caso se estabeleça uma conexão e se crie a possibilidade de se somar uma [a consciência ordinária] ${ }^{5}$ a outra [a consciência expandida] (Attisani, 2006, p. 60).

Somos conformados por nossas mind structures ${ }^{6}$, estruturas culturais, sociais e religiosas que nos produzem como sujeitos - produzem nossos modos de pensar, sentir, agir, ou seja, nossos modos de (nos) perceber (Grotowski falava na produção de nossas 'imagens de mundo' ou nossas 'estruturas de pensamento'), e, portanto também nossa identidade, o lugar/os lugares onde dizemos 'eu'. Para podermos 'pensar' sobre o que pensamos, 'sentir' aquilo que sentimos, 'agir' sobre o que fazemos mecanicamente, é necessário um outro tipo de atenção, um trabalho sobre a percepção que nos liberte - ainda que momentaneamente - de nossa prisão identitária. Dizia Grotowski:

Frequentemente, uma incrível quantidade de estímulos está fluindo em nossa direção, do lado de fora algo está 'falando' conosco todo o tempo, mas somos programados de tal maneira que nossa atenção registra exclusivamente aqueles estímulos que estáo em acordo com a nossa imagem do mundo que foi aprendida (Grotowski, 1997 [1980/1981/1982], p. 259).

Esse trabalho sobre a percepção será, necessariamente, um trabalho sobre a presença. Presença vista aqui náo como força individual ou carismática, mas como modo de participaçáo e de encontro com o mundo, de desmanche das crispaçóes, de ancoramento no hic et nunc. No Workcenter, trata-se também da preparação/descoberta de um corpo-canal para a circulação das energias, do qual falaremos mais adiante. Energia é também um termo que Grotowski utilizava para substituir a palavra espiritual. Dizia:

Eu trabalhava e trabalho ainda com pessoas de horizontes filosóficos e religiosos muito diferentes; o que eu fazia devia ser ao mesmo tempo compreensível a todos e ao mesmo 
tempo náo reduzido a uma única visão daquilo que existe. É também por isso que evito a palavra 'espiritual' e falo em 'energia': isso não pertence a igreja alguma, a seita alguma, a ideologia alguma. É um fenômeno que todos podem experimentar (Grotowski, 1996 [1995], s. p.).

Vemos, nessa citação de Grotowski, a importância de certos protocolos pragmáticos dos quais falaremos mais à frente. $\mathrm{O}$ que se investiga deveria poder ser experimentado por todos, mas não precisaria receber dos participantes a mesma nominação, a mesma explicação. A narração da experiência (a maneira de lê-la a posteriori, de explicá-la) poderia (ou não) estar afeita à mind structure de cada um, mas a própria experiência é concebida como um lugar objetivo, lugar de escape daquelas mesmas estruturas mentais que organizam a percepção.

O trabalho sobre o alargamento da percepção e aquele sobre a energia são, para Grotowski, um mesmo trabalho. Falava, em texto de 1979, Ipotesi di Lavoro, de dois muros que oprimiriam o ser humano: o muro colocado às percepçóes, aos sentidos humanos - incapazes de perceber outra coisa senáo aquilo a que já estavam acostumados - e o muro colocado às forças, às energias que habitam natureza e homens e das quais estaríamos afastados. Depois de separar didaticamente esses muros, dizia tratar-se, na realidade, de um só. No alargamento das percepçóes, tombava também a barreira colocada às energias que circulam fora/dentro do homem.

\section{III}

De maneira muito impressionista, pode-se dizer que Grotowski, no final de sua investigação no Teatro das Fontes e no Objective Drama, encontrou, principalmente nos cantos afro-caribenhos, os instrumentos de trabalho sobre si que estava procurando quando de suas viagens - com o grupo internacional do Teatro das Fontes - ao México, à Índia, a Bengala e ao Haiti. E, aproximando-nos desses instrumentos, podemos refletir sobre a noção de técnica (diferente de procedimento mecânico) da qual falava Mario Biagini na citação com que abrimos esse artigo.

Grotowski, em determinado momento da sua trajetória, não mais se perguntava - frente a experiências que o interessavam - se aquilo era arte/teatro ou náo, perguntava-se sobre o que aqueles praticantes sabiam sobre o ser humano, ou especificando ainda mais, sobre "[...] as leis que dirigem o comportamento humano numa situação 
extracotidiana"7 (Grotowski, 1995, p. 11). Estava buscando técnicas - se quisermos manter uma nomenclatura de Foucault, diríamos técnicas de si-simples, dramáticas e orgânicas ${ }^{8}$. Por questóes de espaço, abordarei de maneira não exaustiva essas noçóes. Necessário dizer que foi a partir do espetáculo $O$ Príncipe constante, e da experiência vivenciada com Cieslak, que a noção de organicidade ou de consciência orgânica entrou no vocabulário de Grotowski, passando a ser mesmo uma lente através da qual Grotowski abordava o trabalho do ator e, posteriormente, não mais do ator, mas dos participantes de suas outras fases. Com essa mesma lente, Grotowski foi em busca das técnicas que lhe interessavam. No Collège de France, ao traçar didaticamente uma separação - no ritual e no teatro - entre as linhas orgânicas e artificiais, Grotowski dizia ter trabalhado na linha orgânica - assim como Stanislavski (no teatro) e como o vudu (no ritual), para dar apenas dois outros exemplos citados pelo próprio Grotowski.

Para falar sobre as técnicas simples (não complexas), gostaria de citar um fragmento do texto de Grotowski Tu es le fils de quelqu'un, de 1985. Retomaremos essa citação mais à frente quando formos refletir sobre a relação entre as investigações realizadas no Workcenter com os cantos tradicionais haitianos e a tradiçáo do vudu.

Grotowski, nesse texto, falava da sua busca por saberes que estivessem relacionados com a utilização da 'energia primária' do corpo. As imagens - "[...] falo de tudo isso por imagens sem nenhuma pretensão científica" (Grotowski, 1993 [1985], p. 71) - iam da serpente adormecida do tantra, passando pelo cérebro réptil (“[...] cérebro que é o mais velho, e que começa na parte posterior do crânio e baixa ao longo da coluna vertebral" - (Grotowski, 1993 [1985], p. 71)), até a cobra da cultura afro-caribenha. Grotowski dizia que, buscando esses saberes, tinha feito várias viagens, lido vários livros e encontrado vários rastros.

Logo em seguida, no texto, apresentava o exemplo de uma técnica que havia visto no deserto do Kalahari e afirmava que, embora essa técnica trabalhasse exatamente sobre o que estava lhe interessando, ele náo poderia utilizá-la - por sua complexidade - como instrumento de trabalho:

[...] a técnica [...] consiste em fazer 'ferver a energia', como eles dizem. Fazem isso através de uma dança extremamente precisa. Essa dança complicada e muito longa (leva horas e horas) não poderia ser empregada por mim como instrumento: primeiro, é muito complexa, segundo, está muito 
ligada a uma estrutura mental da gente do Kalahari, terceiro, para os Ocidentais seria quase impossível resistir um tempo longo sem perder o equilíbrio psíquico. Então, nem pensar [...] (Grotowski, 1993 [1985], p. 71).

Ao falarmos da busca por técnicas simples, não complexas, creio que - e essa citação é emblemática - vemos o grau de responsabilidade e de aguda investigaçáo envolvidos, naquela época, no trabalho de Grotowski. Trata-se, verdadeiramente, de um pesquisador - ainda que sua pesquisa pareça, a olhos racionalistas, misteriosa ou esotérica. Estamos muito longe de qualquer encantamento new age, sincretismo fácil (junçáo de partes de diferentes rituais) ou busca de beleza formal (uma bonita dança exótica para ser colocada em um futuro espetáculo). Grotowski estava em busca de instrumentos de trabalho sobre si, e sabia o grau de risco envolvido nesta investigação. Procurava, então, técnicas simples, ou seja, que não precisassem - pelo grau de dificuldade de execução - terem sido aprendidas desde criança, e que, mais do que isso, fossem afeitas à psique e a mind structure dos Ocidentais (para que esses não naufragassem, por exemplo, nos conteúdos inconscientes que pudessem surgir). Buscava instrumentos que pudessem realmente funcionar transculturalmente.

No que diz respeito às técnicas dramáticas, podemos dizer que Grotowski traça uma oposição entre essas e as técnicas que chama de contemplativas ou meditativas (Grotowski, 1997 [1980/1981/1982], p. 260-261). Nas técnicas meditativas - Grotowski as exemplificava com a yoga de orientação clássica (Patanjali -Yoga Sutras) - buscarse-ia (a expressão é de Mircea Eliade, citado por Grotowski) um "descondicionamento da dependência do tempo e do espaço". "Tratase teoricamente (eu repito: teoricamente) da suspensão de um triplo processo: do movimento, da respiraçáo e do pensamento. Os sentidos, a percepçáo sensível, devem ser retirados do contato com a realidade exterior" (Grotowski, 1995, p. 16) Já nas técnicas dramáticas, o organismo estaria em movimento, em ação, em inter-relação, em contato com o mundo exterior, com os outros seres humanos e com a natureza. Há inevitavelmente uma semelhança entre as técnicas chamadas dramáticas e aquelas orgânicas que veremos a seguir (ou entre as meditativas e as artificiais). Algumas vezes Grotowski as utiliza como sinônimos, já que as técnicas meditativas se dirigiriam, "conscientemente 'contra a natureza", em direçâo a "um ralentar dos processos vitais'" (Grotowski, 1995, p. 16) e, ao contrário, nas 
técnicas orgânicas, como veremos, seria preservada e mesmo reforçada/intensificada a fluidez dos processos orgânicos.

Vamos, então, às técnicas orgânicas. Grotowski falava, nas aulas do Collège de France, em técnicas artificiais (ou, de maneira mais ampla, em linha artificial) em oposição àquelas orgânicas (ou linha orgânica, linha na qual ele localizava seu próprio trabalho). Na linha orgânica, a vitalidade, as energias vitais não são vistas como algo que precisaria ser ralentado, paralisado ou controlado, mas, ao contrário, as técnicas buscam intensificar esses processos colocando-os a serviço de, para usarmos a expressão que escolhemos nesse artigo, um trabalho sobre si. Já começamos a tocar nesse ponto quando, mais acima, dissemos que Grotowski buscava, nas diversas técnicas elaboradas nas tradiçôes, àquelas vinculadas às forças primárias do corpo.

Quando Grotowski dizia ter optado pela linha orgânica, afirmava ter optado por trabalhar a partir do que chamou dos motores do homem, a partir das forças vitais, sobre o - e a partir da aceitação do - encarnado. Grotowski dizia que trabalhar nesse território tinha a ver com não querer "separar-se das contradiçôes", não querer "deter ou aniquilar uma parte da nossa natureza" (Grotowski, 1970 [1968], p. 229).

O corpo, a carne, a natureza, não necessitavam ser rejeitados, superados ou controlados, mas, se experimentados em sua potencialidade última, poderiam alargar a percepção que se tem tanto do próprio corpo quanto da própria identidade. E, assim, "Aquele que descobre o corpo, descobre os corpos no plural [...] Aquele que descobre seu corpo, para descobri-lo deve descobrir o corpo de um outro. Não como um estudioso, mas como alguém que ama. E entáo ele descobre o corpo de todas as outras coisas" (Grotowski, 1978, p. 3).

Por outro lado, havia riscos - e precauções - a serem levados em conta nesse trabalho. No texto L'art du debutant, Grotowski falou em Alta Obediência ou Alto Abandono para se referir à essa aceitaçáo, no trabalho, das forças vitais. Dizia que era necessário permitir-se ser levado por essas forças e sempre se esforçar para não ser engolido por elas; preservar esta força, sem ser destruído. Outra expressão utilizada por Grotowski talvez ajude a clarear ainda mais esse ponto. Grotowski falava do homem como aquele que está de pé no início. As forças inconscientes, arcaicas, as forças vitais, animais (o início) não são vistas como negativas. Trabalha-se aceitando - preservando - o estar no início, mas, por outro lado, deve-se estar de pé, ou seja, não ser engolido por essas mesmas forças. 
Falando sobre os cantos de tradição, em relação a esse mesmo problema, Grotowski disse:

Quando se começa a captar as qualidades vibratórias [dos cantos] isso encontra sua radicação nos impulsos e nas açóes. E então, de repente, aquele canto começa a cantarnos. Aquele canto antigo me canta: não sei mais se descubro aquele canto ou se sou aquele canto. Atenção! Atenção! É o momento que requer vigilância, não tornar-se propriedade do canto - sim, estar de pé (Grotowski, 2007 [1989/1990], p. 217).

Voltando à oposição orgânico/artificial, Grotowski dizia que os cantos de tradiçáo com os quais trabalhava, ao contrário dos mantras que ele considerava como vinculados à linha artificial, estavam "radicados na organicidade". Eram "cantos-corpo" já que a qualidade vibratória estava vinculada aos impulsos e a pequenas ações: "[...] porque os impulsos que correm no corpo são justamente aqueles que trazem aquele canto" (Grotowski, 2007 [1989/1990], p. 237).

Os cantos afro-caribenhos fazem parte, então, das técnicas simples, dramáticas e orgânicas que Grotowski buscou. São instrumentos para um tipo de investigação - sobre a verticalidade (veremos essa noção/prática mais à frente) - que passou a interessar, cada vez mais, a Grotowski.

Agora, vamos nos debruçar sobre a relação canto/cantante e entrar, mais fortemente, na discussão tradição/investigação no trabalho de Grotowski e do Workcenter. Para isso, seguiremos, de perto, os ditos e escritos dos artistas responsáveis por essa pesquisa.

\section{Como será que isso era esse som que hoje sim gera sóis, dói em dós ${ }^{9}$, a questão da objetividade}

Acabamos de ver que tipo de instrumentos/de técnicas Grotowski procurou, e, agora, é importante também entender - ainda que superficialmente - de que modo esses instrumentos são trabalhados/ abordados pelos atuantes. Para falar sobre isso, teremos que analisar o par tradição/investigação, assim como ele acontece nas últimas fases do trabalho de Grotowski e no Workcenter. E, entáo, devemos pensar esses instrumentos em termos de suas qualidades pragmáticas. Grotowski (1997 [1991], p. 130), em entrevista sobre Gurdjieff ${ }^{10}$, falava justamente da capacidade que Gurdjieff tinha de dissociar os elementos tradicionais de seus conteúdos teológicos, devolvendo-os às suas qualidades pragmáticas. 
No seu projeto para entrada no Collège de France, Grotowski dizia que duas questôes - poderíamos dizer pragmáticas - haviam pautado suas investigaçóes: "1) Existem elementos técnicos que ultrapassem o contexto cultural no qual esta ou aquela forma de prática ritual nasceu e/ou se desenvolveu?" e "2) Esses elementos são objetivos o suficiente para continuarem eficazes no caso de pessoas pertencentes a um outro contexto cultural, tradicional e religioso?"(Grotowski, 1995, p. 11). Indicava aqui a direção precisa de seu trabalho: uma investigação transcultural na busca de técnicas eficazes - simples, dramáticas e orgânicas - de trabalho sobre si.

Esse trabalho está, portanto, relacionado com experiências diretas, corpóreas, tangíveis de cada ator/atuante. Não se trata aqui de uma questão de crença, nem da aplicação de procedimentos vistos como dogmas. Esta é uma investigação rigorosa que utiliza elementos de tradiçôes, mas é, ao mesmo tempo, uma busca contemporânea, e, portanto, não vinculada a nenhuma religião ou tradição específica, pois, "[...] é justamente não recorrendo a etiquetas filosóficas ou teológicas que se pode chegar a tocar um nervo transcultural" (Grotowski apud Attisani, 2006, p. 55).

No Workcenter, por exemplo, embora se utilizem elementos (ou se importem instrumentos) - cantos, passos - da tradiçáo vudu, não há nenhum tipo de conversão a essa tradição. Os elementos são utilizados, como diz Grotowski, pela sua capacidade de impactar diretamente "o corpo, o coração e a cabeça dos atuantes" (Grotowski, 2007 [1989/1990], p. 232).

Thomas Richards fala desse impacto - em suas entrevistas - de inúmeras formas. Escolhi uma delas:

Tudo tem a ver com a sua qualidade [dos cantos], nossos cantos são especialmente escolhidos pela sua eficácia em colocar você mesmo frente a partes de você mesmo, têm a capacidade de chamar a sua alma ao seu ouvido. Por exemplo, você pode escutar um canto e sentir que você está realmente ouvindo, mas chega um momento em que algo dentro de você começa a ouvir, mas não é mais a orelha! Uma das peculiaridades desses cantos é chamar este algo de você para fora, para frente, da sua profundidade para sua superfície, e isso tem a ver com os diferentes aspectos de você mesmo, com a sua vida emocional, com a parte de você que prefere manter escondida na vida cotidiana ou que está relacionada com a força da sua vida, aquela força que leva você através das mil atividades que realiza durante todo o dia, e que te diz: 'eu quero isso!', uma espécie de 
fogo, uma força que gosta inclusive de ver sua marca na vida (Richards apud Attisani, 2006, p. 140).

Richards fala exatamente do impacto dos cantos e do 'trabalho' que eles podem realizar sobre o atuante/cantante. Mostra, ainda, as forças vitais e emocionais como parte integrante do trabalho, como já havíamos assinalado. Essas forças, que identificamos a cada momento, de modo confuso e inconsciente, com um 'eu', vão sendo chamadas - com o canto - à superfície, para fora, como diz Richards, para poderem trabalhar, talvez, em outra direçáo que não aquela identitária/individual. Nesse mesmo sentido, lembro-me que na entrevista que me concedeu ${ }^{11}$, Richards disse-me que as forças emocionais, por exemplo, antes de serem nomeadas, rotuladas - a raiva, o amor, a inveja - são apenas (e nesse apenas não estou subestimando essas forças, ao contrário) forças/ diferentes qualidades de energia que vão - se liberadas daqueles primeiros rótulos e das possíveis crispaçóes relacionadas a certas vivências da vida de cada atuante - operar no trabalho.

Podemos criticar Grotowski por uma utilizaçãolimportação de elementos de outra cultura sem uma vinculação estreita com suas crenças, rituais e fé. Mas, em primeiro lugar, é necessário afirmar que, em Grotowski e no Workcenter, isso não fala de um desconhecimento desta outra cultura (ou de um desinteresse por ela), mas é uma escolha que se faz como investigador.

Em certo sentido, pode-se dizer que há mesmo algo de blasfemo - embora esse seja um termo de Grotowski cunhado na fase na qual montava espetáculos - nessa escolha dos instrumentos por suas qualidades pragmáticas. Perceber o que pode funcionar fora de um sistema de crenças, de uma religiáo e/ou cultura, aproximanos, de certa forma, da imagem do místico (assim como a conceitua Bergson). E sabemos que os místicos, falando de um Deus que se pode experienciar, falando, como Santa Teresa D'Ávila, das moradas e quartos - no seu próprio corpo - para a presença de Deus, colocaram em questão a religiáo/poder estabelecida(o). E sofreram, por isso mesmo, por essa blasfêmia, puniçóes. Por outro lado, vê-se, nesses mesmos nomes tão importantes para Grotowski, como Teresa D’Ávila e San Juan de La Cruz, entre outros, e nas suas experiências, um exemplo de trabalho sobre si e um convite à experimentação de uma alteridade em si mesmo, de um outro de si. Digo isso sem, por outro lado, negligenciar e nem esquecer que na religião dita institu- 
cionalizada, seja ela qual for, muitas outras coisas importantes - que não a questão do poder - estão em operação.

De qualquer forma, o respeito à tradição, para Grotowski, estaria na capacidade de fazer com que os instrumentos de trabalho sobre si, que foram descobertos e deixados, como possível legado, por outros que vieram antes, pelos antepassados, pudessem continuar funcionando e, mais ainda, possam ser, talvez, aprimorados. Aprimorados, porque destilados, porque separados dos dogmas e crenças vinculados a eles.

Fala-se, no Workcenter, em fazer com que os instrumentos funcionem justamente para aquilo que foram criados. E, nessa operaçáo, estaria o respeito - informado, se quisermos, pela blasfêmia - à tradição.

Por outro lado, como vimos na citaçáo sobre o ritual do deserto do Kalahari, Grotowski não era nada ingênuo com relaçáo ao que via e investigava. Percebia que não poderia utilizar certas técnicas porque o homem ocidental iria submergir nessas experiências, submergir no conteúdo inconsciente aflorado. Isso significa que Grotowski levava em consideração, mesmo que para ir além dela, a mind structure de seus atuantes/praticantes. Por isso e muitas outras coisas, Peter Brook (2011 [1999], p. 62) falava de Grotowski como de um "cientista espiritual". Dizia que, no trabalho do artista polonês, trata-se de verificação e não de crença. Verifica-se a potência, a eficácia dos instrumentos de trabalho sobre si, sem que se esteja vinculado a uma maneira de pensar e/ou a uma fé que ligasse, previamente, os praticantes a esses instrumentos.

\section{Casca oca, a cigarra cantou-se toda ${ }^{12}$, relaçáo canto/cantante}

Falamos em qualidades pragmáticas, mas não devemos pensar que esses instrumentos operam instantaneamente como se se tratasse de um botão que se aperta para que algo funcione. Ao contrário, o canto é como - e utilizo imagens dos textos de Richards ou Biagini - um mapa ou território que o viajante tem que percorrer; uma carta dos antepassados a ser lida/decifrada pelo cantante; ou é mesmo uma pessoa de quem o cantante se aproxima, que ainda vai conhecer; há mesmo a possibilidade do atuante perguntar ao canto - no ato de cantar - como ele desejaria ser cantado. O canto, portanto, náo é visto, nesse trabalho, como um objeto a ser manipulado por um sujeito, mas há um vai e vem entre canto e cantante. Kris Salata diz 
isso belamente: "O cantor que 'esquece de si mesmo' no canto [...] e o canto que 'recorda' [...] O canto se revela através do atuante, enquanto o ser humano o faz através do canto...”(Salata, 2007, p. 241). Aparece, naquelas imagens e nessa citação, uma maneira de abordagem da qual vimos falando todo o tempo neste artigo: aquela em que a artesania é, ao mesmo tempo, transformação de si. Quando 'se esquece de si', o cantante é outro e é justamente esse outro que o canto recorda e faz recordar. Perde-se aqui qualquer posiçáo previamente definida de sujeito e objeto: homem e canto estão em acoplamento, em rede.

É nesse sentido que Mario Biagini, criticando a busca e utilizaçâo crescente - de um determinado tipo de teatro - por técnicas tradicionais e/ou espirituais, diz "Mas onde estáo as fontes antigas? Estamos de acordo, aquilo de que temos necessidade não é de arqueologia, mas de uma água viva. [...] As fontes antigas somos nós" (Biagini, 2007a [2003/2006], p. 409). Não adiantaria acumular - e utilizar - histórias tradicionais, cantos de diferentes tradiçóes, danças de diferentes povos se não houvesse a perspectiva de um trabalho sobre si, se náo se buscasse a objetividade e funcionalidade desses instrumentos - e, nesse sentido, Grotowski comunga com uma perspectiva tradicional e náo estética na utilização do material - junto ao corpo (corpo-canal, corpo-vida) do homem que canta, dança ou conta.

O homem é, nessa perspectiva, ele também, instrumento para algo. Biagini afirma, por exemplo, que o cantar "[...] está cheio da vida, dos desejos, da intimidade daquela pessoa [que canta]. E junto com isso há alguma coisa de não pessoal que aparece. A pessoa é canal, o indivíduo - com as suas idiossincrasias e com sua biografia - não foi dissolvido, não desaparece, ele está a serviço de alguma coisa" (Biagini 2007a, p. 416). Para entendermos melhor do que se trata, podemos fazer a diferença entre um trabalho sobre si e um trabalho para si: no Workcenter, digamos que há um si que se oferece inteiramente e de modo lúcido - sua vitalidade, afetividade, atenção aguçada, desejo - para que um certo trabalho se faça sobre ele. Concordo com De Marinis quando diz que, no Workcenter,

Não se pode dizer que se trata de um trabalho para si mesmo, no qual o indivíduo seja o primeiro e único beneficiário. A ideia, ao contrário, é considerar o indivíduo como um âmbito de busca, como um campo, como um laboratório e como um instrumento. [...] o rigor de fazer o indivíduo um espaço para percorrer e não um valor em si mesmo (De Marinis, 2004, p. 90-91). 
Os atuantes, assim como, de certa maneira, também os cantos, são tanto fontes antigas como instrumentos para um determinado trabalho sobre as possibilidades da condição humana.

É importante lembrar também que a competência em relação ao cantar - melodia, ritmo, sonoridade do canto e vibraçáo devem ser precisas - é condição sine qua non para sua efetividade. O canto demanda, solicita a vigilância e a competência do atuante - competência que é sempre um ajustamento, uma adaptação ao momento presente e nunca está resolvida de uma vez por todas (justamente porque se trabalha sobre os processos orgânicos e inter-relacionais).

Aqui o trabalho sobre si não se confunde com qualquer falta de precisão, com qualquer zona de conforto, subjetivismo ou abstração. Não se trata de buscar o prazer, a felicidade ou o autoconhecimento, produtos típicos da sociedade em que vivemos. Para Grotowski, na impecabilidade ou não daquilo que se faz, estaria o indicador de uma lucidez frente à chamada investigaçáo interior. Impecabilidade do artesanato não é preceito moral ou virtuosismo, diz respeito à luta que é preciso empreender exatamente contra os muros da percepção e das forças a que nos referimos mais acima. A competência é, ao mesmo tempo, uma competência artesanal e uma competência de si.

\section{E os anjos sobem e descem, a verticalidade}

Grotowski dizia, no projeto do Collège de France, que o objetivo das práticas rituais orgânicas era a "[...] transformaçấo da energia cotidiana, pesada, mas plena de vida, algumas vezes violenta, ligada à sensualidade, em energias leves, digamos sutis" (Grotowski, 1995, s. p.). Falava que o corpo era o veículo dessa passagem. Referia-se não ao corpo da anatomia médica ocidental, mas a um corpo canal - podemos pensar nos chakras para termos uma referência - para e das energias. Grotowski, quando fala da transformação das energias vitais em sutis e (embora não apareça na citação acima) na também necessária volta à densidade do corpo mantendo a presença dessas energias mais sutis, se referia ao que nomeou, em textos e palestras do final dos anos 1980 e dos anos 1990, como 'verticalidade'. Dizia que o conteúdo da arte como veículo - nome da última fase de trabalho que foi (e é) materializada nas Actions - era justamente a verticalidade. Oferecia diferentes imagens para esse conteúdo, e uma deles era a escada de Jacó com os anjos subindo e descendo. 
Richards refere-se também à verticalidade e outras vezes, como forjando também um vocabulário pessoal, à ação interior. Na citação que apresento a seguir, a ideia de transformaçáo de energia relacionada a um trabalho sobre si pode ficar mais clara:

Um dos significados da palavra yoga é jugo, o instrumento com o qual se une dois animais para orientar a sua força. Grotowski usava essa palavra referindo-se a um trabalho sobre si no qual se coloca a própria força sob um jugo, visando um movimento interior. A própria força começa a subir em torno de um eixo, como sobre uma árvore, e a dirigir-se como em direção a uma fonte de energia que reside mais acima; e depois qualquer coisa dessa fonte leve desce, penetra suavemente e lava [Verticalidade]. Pode iniciar um diálogo entre diversas fontes em nós [o que Grotowski chamou, como vimos mais acima, de cabeça, coração, mente] e uma determinada fonte, uma qualidade de energia que não te pertence. Não podemos dizer que é nossa, mas podemos nos avizinhar, tocá-la. É este o tipo de jugo que estamos procurando, e suponho que era isso verdadeiramente que me atraia em Grotowski e na sua investigação (Richards, 2007 [2003/2006], p. 111).

Mas, talvez porque também falamos muito sobre subjetividade neste artigo, eu prefira apontar para o fim desse escrito com uma fala de Mario Biagini sobre esse mesmo aspecto, sobre a verticalidade, na qual ele aponta para uma transformação da percepção/qualidade do 'eu'. Diz Biagini:

[...] na verticalidade, é aquela vaga sensação que identifico como 'eu' que muda de qualidade, como se o meu ser, a minha percepção de mim no mundo e do mundo em mim mudassem de qualidade, de densidade. [...]

Há momentos em que ando pela rua e é como se vivesse e percebesse o mundo a partir de debaixo do meu umbigo: me movimento, sento, vejo, penso como se fosse um trator; a percepção, as impressôes que tenho das pessoas são densas, espessas, pesadas, há algo de inerte em mim [...] Então, um segundo depois, acontece algo e imediatamente as cores são diferentes, vívidas, improvisadamente os meus pensamentos estão em uma outra relação comigo, não me pertencem; é como se, em mim, eu estivesse em um outro lugar, ou em um outro nível ou plano [...]. Não vejo mais só eles, os outros, vejo que cada um é um mistério; não existe apenas eu, mas cada coisa é 'eu', cada coisa diz 'eu' (Biagini, 2007c [2000], p. 50-51).

Pode-se dizer que o trabalho sobre si, no Workcenter, trabalho baseado na verticalidade, aponta para uma maneira outra de estar no mundo, muito menos individualista e talvez também muito menos antropocêntrica. 
O si que aparece no trabalho, na verticalidade (para usar a terminologia grotowskiana), comporta um virtual desaparecimento do corpo do performer em favor de uma 'transparência' [...] na qual os traços do 'eu', do 'tu' e do 'outro' estão confundidos e o lugar-juntos se torna o novo sujeito, passageiro, de uma consciência e de uma transcendência (Attisani, 2006, p. 83).

\section{Aquele senhor polonês lançou um desafio: "Cantem, pode acontecer alguma coisa?", o acontecimento}

Para finalizar, apresento a citação completa de onde retirei o título do artigo.

Lembro-me de quando era criança - vivia em uma fazenda: sai de casa e tudo é novo, você percebe que começou a primavera, o mundo é leve, o mundo é um milagre e você sente que pertence a isso, que faz parte. E ao mesmo tempo, que não é ninguém, e desse ser ninguém, como uma gaiola que se quebra, uma alegria é percebida. Aquele senhor polonês lançou um desafio: "Cantem, pode acontecer alguma coisa?" Através dele e desses cantos, descobrimos uma possibilidade? Talvez, pequena: alguma coisa pode acontecer através desses cantos. E como se improvisadamente aquela luz, aquelas cores daquela manhã nos revisitassem - eu, ninguém: uma gaiola que se abre por um momento. Naquele momento, algo funciona de novo e de novo: "Veja, é um milagre. Esse mundo é leve e eu faço parte disso tudo". E, depois, talvez ainda mais um pouco: "Esse mundo é um milagre. Eu, quem?”. Depois acaba, e às vezes permanece em você e com você como uma ressonância. Não se está melhor do que antes, só se tentou voltar para casa (Biagini, 2007c, p. 50-51).

Pode-se ver que é um outro de si que aparece quando o trabalho sobre si relacionado aos cantos de tradição - ancorados nos impulsos do corpo, na organicidade, e na direção da verticalidade - funcionam. Um eu partícipe do mundo, passante (be passers-by, diz Jesus no evangelho apócrifo de Tomé utilizado na Action), um eu-ninguém, menos aferrado/identificado às construçóes do ego, mesmo controlado pelos comandos mentais e, ao mesmo tempo, menos submetido (por isso Grotowski disse, na aceitaçáo da organicidade, tratar-se de um Alto Abandono) a forças inconscientes, emotivas e vitais. Importante salientar que essa 'volta à casa', da qual fala Biagini, não é um lugar estabelecido de uma vez por todas, mas uma espécie de direção a ser investigada a cada ação, a cada momento, hic e nunc, é um acontecimento. 


\section{Notas}

${ }^{1}$ Citação retirada do filme "A Postcard from Opole", de 1963. Se não houver nota específica, todas as traduçóes de textos em língua estrangeira foram feitas pela autora.

${ }^{2}$ Como estudiosa, tenho me esforçado por fazer esse caminho ao estudar as noções forjadas por Grotowski em seus escritos: vê-las na sua relaçáo com o contexto material e com as experiências práticas desenvolvidas por Grotowski. O livro "Palavras Praticadas: o percurso artístico de Jerzy Grotowski (1959-1974), recentemente lançado pela Perspectiva, faz parte desse esforço.

${ }^{3}$ No sentido de contextualizar os textos de Grotowski, tenho optado por, ao citá-los, colocar a data da publicação de onde retirei a citação seguida, entre parênteses, da primeira data relativa ao texto de que disponha, seja uma primeira publicação ou mesmo a data da palestra ou encontro que tenha dado origem ao texto. Fiz isso também com os textos de Biagini e Richards.

${ }^{4}$ Para irmos um pouco mais longe, lembro-me de uma resposta de Thomas Richards à plateia no ECUM 2011. Perguntado se os atuantes das Actions conheciam o sentido das palavras dos cantos que cantavam, já que os cantos eram, em sua maioria, afro-caribenhos, e os artistas eram europeus e americanos, Richards afirmou que o conteúdo, o sentido que cada canto trazia era performativo. O conhecimento do canto só poderia ser obtido ao cantá-lo. Era necessário captar e desenvolver o núcleo vibratório de cada canto (que é diferente do que entendemos como melodia). Mais do que isso, o sentido ou o conhecimento do canto estaria ligado ao impacto e à transformaçáo que ele operaria nos atuantes enquanto cantassem. Apareceria na transformaçáo da própria noção de si daquele que canta e enquanto canta.

5 Sempre que apareçam, nas citações, colchetes [ ] significa uma intervenção da autora.

${ }^{6}$ Grotowski utilizou inúmeras vezes a expressão mind structure no curso "Tecnique Originaire dell'Attore" que ministrou em 1982 na Universidade de Roma, La Sapienza. A transcrição e traduçáo do curso foi feita por Luisa Tinti, mas os textos não foram nem revistos pelo autor e nem publicados. Retiro as citaçóes da brochura que me foi gentilmente cedida por Tinti.

${ }^{7}$ A tradução do texto de Grotowski "Projet d'Enseigment et de Recherches - Antropologie Théâtrale, projeto apresentado para candidatura de Grotowski ao Collège de France (1995) é de Laila Garin.

${ }^{8}$ Utilizou também a expressão 'técnicas ecológicas' para referir-se àquelas que técnicas eram "ligadas às forças da vida, ao que chamamos de mundo vivente, cuja orientação podemos descrever, do modo mais simplificado possível, como não estar cortado (não estar cego ou surdo) face àquilo que está fora de você” (Grotowski, 1997 [1980/1981/1982], p. 259).

9 Verso da música "Genipapo Absoluto" de Caetano Veloso.

${ }^{10}$ Místico e mestre espiritual Greco-armênio, nascido em 1866.

${ }^{11}$ A entrevista, de 1999, foi publicada posteriormente no livro de Thomas Richards, Heart of Practice: within the Workcenter of Jerzy Grotowski and Thomas Richards, Routledge, 2008, sob o título de "As an Unbroken Stream".

${ }^{12}$ Hai kai de Matsuo Bashô. 


\section{Referências}

ATTISANI, Antonio. Un Teatro Apocrifo. Il Potenziale dell'Arte Teatrale nel Workcenter of Jerzy Grotowski and Thomas Richards. Miláo: Edizioni Medusa, 2006.

BIAGINI, Mario. Desiderio Senza Oggetto. In: BIAGINI, Mario; ATTISANI, Antonio (Org.). Opere e Sentieri - Il Workcenter of Jerzy Grotowksi and Thomas Richards. Roma: Bulzoni Editore, 2007a [2003-2006]. P. 401-420.

BIAGINI, Mario. Conversazioni Informali. In: BIAGINI, Mario; ATTISANI, Antonio (Org.). Opere e Sentieri - Il Workcenter of Jerzy Grotowksi and Thomas Richards. Roma: Bulzoni Editore, 2007b. P. 255-300.

BIAGINI, Mario. Seminario a 'La Sapienza', ovvero della coltivazione delle cipolle In: ATTISANI, Antonio; BIAGINI, Mario. Opere e Sentieri - Il Workcenter of Jerzy Grotowski and Thomas Richards. Roma: Bulzoni Editore, 2007c. P. 21-62.

BROOK, Peter. Para ir Além do Teatro. In: Avec Grotowski. Brasília: Teatro caleidoscópio e Editora Dulcina, 2011 [1999]. P. 55-63.

DE MARINIS, Marco. La Parábola de Grotowski: el secreto del 'novecento' teatral. Buenos Aires: Galerna, 2004.

FOUCAULT, Michel. La Hermenéutica del Sujeto. Buenos Aires: Fondo de Cultura Econômica, 2009.

FOUCAULT, Michel. A Hermenêutica do Sujeito. São Paulo: Martins Fontes, 2010.

GROS, Frédéric. Situation del Curso. In: FOUCAULT, Michel. La Hermenéutica del Sujeto. Buenos Aires: Fondo de Cultura Económica, 2009. P. 479-516.

GROS, Frédéric. Situação do Curso In: Foucault, Michel. A Hermenêutica do Sujeito. São Paulo: Martins Fontes, 2010. P. 455-494.

GROTOWSKI, Jerzy. Da Companhia Teatral à Arte como Veículo. In: FLASZEN, Ludwik; POLLASTRELLI, Carla (Org.). O Teatro Laboratório de Jerzy Grotowski 1959-1969. São Paulo: Fondazione Pontedera Teatro/Ediçōes SESCSP/Perspectiva, 2007 [1989/1990]. P. 226-243.

GROTOWSKI, Jerzy. "Entrevista a Jerzy Grotowski par Margo Glantz". In: GROTOWSKI, Jerzy. Hacia un Teatro Pobre. México/Argentina/Espanha: Siglo veintiuno editores sa, 1970 [1968]. P. 223-233.

GROTOWSKI, Jerzy. Projet d'Enseigment et de Recherches - Antropologie Théâtrale. Projeto apresentado para candidatura de Grotowski ao Collège de France, 1995. Arquivo de Mario Biagini cedido à pesquisadora.

GROTOWSKI, Jerzy. “O Que Restará depois de mim”. In: Workcenter of Jerzy Grotowski and Thomas Richards. Brochura do simpósio realizado em set./out. 1996 em São Paulo. Transcrição da entrevista realizada por Jean-Pierre Thibaudat para o jornal Libération. Publicada em 26 jul. 1995.

GROTOWSKI, Jerzy. Theatre of Sources. In: SCHECHNER, Richard; WOLFORD, Lisa. 
The Grotowski Sourcebook. Londres e Nova York: Routledge, 1997 [1980/1981/1982]. P. 252-270.

GROTOWSKI, Jerzy. Era como un Volcán. In: Georges Ivanovitch Gurdjieff. Venezuela: Editorial Ganesha, 1997 [1991]. P. 117-137.

GROTOWSKI, Jerzy. L'Art du Débutant. International Theatre Information, printempsété. Paris: ITI, 1978. P. 2-11.

GROTOWSKI, Jerzy. Le Performer. In: Workcenter of Jerzy Grotowski. Brochura em inglês, italiano e francês do Workcenter, 1988 [1987]. P. 53-57.

GROTOWSKI, Jerzy. Tú eres Hijo de Alguien. Máscara - Cuaderno Iberoamericano de Reflexion sobre Escenologia, México, ano 3, n. 11-12, p. 69-75, 1993 [1985].

MOTTA LIMA, Tatiana. Palavras Praticadas: o percurso artístico de Jerzy Grotowski (1959-1974). São Paulo: Routledge, 2012.

RICHARDS, Thomas. Heart of Practice - within the Workcenter of Jerzy Grotowski and Thomas Richards. Londres e Nova York: Routledge, 2008.

RICHARDS, Thomas. Maestro di Nessuna Scusa. In: ATTISANI, Antonio; BIAGINI, Mario (Org.). Opere e Sentieri - Il Workcenter of Jerzy Grotowski and Thomas Richards. Roma: Bulzoni Editore, 2007. P. 109-129.

SALATA, Kris. Prossimità con The Twin: appunti critici su An Action in creation. In: ATTISANI, Antonio; BIAGINI, Mario (Org.). Opere e Sentieri - Il Workcenter of Jerzy Grotowski and Thomas Richards. Roma: Bulzoni Editore, 2007. P. 223-254.

VELOSO, Caetano. Genipapo Absoluto. Intérprete: VELOSO, Caetano. Estrangeiro, Polygram/Philips, 1989. 1 CD.

Tatiana Motta Lima é professora adjunta da Graduação (Departamento de Interpretação) e da Pós Graduação (PPGAC e PPGEAC) da Universidade Federal do Estado do Rio de Janeiro (UNIRIO). Autora do livro Palavras Praticadas, o percurso artístico de Jerzy Grotowski (1959-1974), Perspectiva, 2012. Atriz e diretora bissexta. Ministra oficinas de formação e reciclagem de atores. Coordena o projeto de extensão "Núcleo de Pesquisa do Ator".

E-mail: tatiana.motta.lima@gmail.com

Recebido em 29 de setembro de 2012 Aprovado em 07 de novembro de 2012 